\title{
Pengaruh Kompetensi, Motivasi dan Pelatihan Aplikasi Sistem Penatausahaan SIMAK-BMN Terhadap Kualitas Kinerja Personil Disbekal TNI AL
}

Ahmad Arifin ${ }^{1 *}$, Binsar Mangaratua Sirait ${ }^{1}$, Daniel Setiawan ${ }^{1}$

${ }^{1}$ Sekolah Staf dan Komando Angkatan Laut (SESKOAL)

Jl. Ciledug Raya No 2, Kompleks Seskoal Kebayoran Lama Kota Jakarta

*ahmadarifin.4959@gmail.com

DOI: https://doi.org/10.21107/rekayasa.v14i2.10865

\begin{abstract}
The research was carried out with the aim of knowing how influential the implementation of training from the application of the State Property Accounting Management Information System (SIMAK BMN) administration system and the motivation and competence of Disbekal personnel to the improvement of the quality of Disbekal personnel's performance. The data collection technique was by distributing questionnaires, where the research population was personnel in the accounting department of BMN at the Disbekal Head Office and DKI Jakarta Regional Office, the entire population of 320 Disbekal personnel in this study was used as a sample. Data analysis using statistical methods with independent variables are competence, motivation, and SIMAK-BMN training, while the dependent variable is the quality of personnel performance. It was found that SIMAK-BMN training had a significant effect on the quality of the performance of the Disbekal personnel, motivation and competence affected the performance of the Disbekal personnel.
\end{abstract}

Keywords : SIMAK-BMN training, motivation, competence, performance quality, Disbekal

\section{PENDAHULUAN}

Sistem Informasi Manajemen dan Akuntansi Barang Milik Negara (SIMAK-BMN) pada Dinas Perbekalan Angkatan Laut (Disbekal) diselenggarakan dengan tujuan untuk menghasilkan data informasi yang dibutuhkan sebagai pertanggungjawaban atas pelaksanaan penggunaan APBN serta pengelolaan dan atau pengendalian Barang Milik Negara (BMN). Aplikasi SIMAK-BMN berfungsi untuk melakukan pengendalian dan pengamanan administratif terhadap BMN (Nasrudin 2015; Ardha 2019). Dimana SIMAK BMN memiliki pengaruh signifikan terhadap pelaporan keuangan, khususnya pada pelaksanaan laporan neraca keuangan, yang terkait dengan rekening untuk persediaan, aset tetap negara maupun aset-aset lainnya, proses pengendalian dan pengamanan administratif, serta sebagai sistem penatausahaan BMN (Nasrudin 2015), perihal rencana pengadaan, rencana pengembangan, rencana pemeliharaan maupun proses dan rencana penghapusan (disposal). Laporan Hasil Pemeriksaan (LHP) Badan Pemeriksa Keuangan (BPK) atas Lembaga Kebijakan

\section{Article History:}

Received: May, 19 ${ }^{\text {th }}$ 2021; Accepted: July, $2^{\text {nd }} 2021$

Rekayasa ISSN: $2502-5325$ has been Accredited by Ristekdikti (Arjuna) Decree: No. 23/E/KPT/2019 August 8th, 2019 effective until 2023
Pengadaan Barang/Jasa Pemerintah (LKPP) pada tahun 2019 di Disbekal masih banyak ditemukan lagi kesalahan mengenai penatausahaan BMN, khususnya adalah penatausahaan aset tetap yang masih belum optimal. Terkait BMN Aset Tetap Tahun 2019 masih banyak yang harus dibenahi dan disempurnakan sehingga dapat meminimalisir temuan-temuan yang bersifat berulang setiap tahunnya. Oleh karena itu, dalam pengelolaan dan pertanggungjawaban atas barang milik negara melalui aplikasi SIMAK-BMN, diharapkan dapat mempengaruhi dan meningkatkan kualitas kinerja personil Disbekal.

Laporan Barang Milik Negara (BMN) merupakan bagian terpenting didalam pengelolaan serta didalam pertanggung jawaban keuangan Negara, dimana perlu disajikan kedalam sebuah Laporan Keuangan (LK). Guna menghasilkan sebuah laporan keuangan yang berkualitas, maka sebuah laporan keuangan harus memenuhi empat kriteria penting agar kualitas laporan keuangan menjadi bukti pertanggung jawaban penggunaan anggaran dari

\section{Cite this as:}

Arifin, A., W., Sirait, B.M \& Setiawan, D. (2021). Pengaruh Kompetensi Motivasi dan Pelatihan Aplikasi Sistem Penatausahaan SIMAK-BMN terhadap Kualitas Kinerja Personil Disbekal TNI AL. Rekayasa 14 (2). 215-221. doi: https://doi.org/10.21107/rekayasa.v14i2.10865.

(C) 2021 Ahmad Arifin 
pemerintah jadi baik, empat kriteria itu antara lain dapat dibandingkan serta dinilai, dapat diandalkan, memiliki relevansi, serta mampu dipahami (Kiswara 2011). Sehingga, kesesuaian antara informasi dengan kebutuhan pembuat keputusan dalam meningkatkan kualitas kinerja personil, dimana kualitas informasi yang buruk dapat mengakibatkan kerugian pada pengambilan keputusan (Ratifah, Ifa, Mochammad 2012) agar dapat meningkatkan kualitas kinerja organisasi. Adapun unsur yang berperan penting pada pengelolaan keuangan adalah motivasi dan kompetensi SDM (Runtuwene, Saerang, and Morasa 2017). Agar dapat terselenggaranya peningkatan kualitas kinerja organisasi tersebut diperlukan pembinaan pendidikan sumber daya manusia TNI $A L$, yang dilakukan melalui proses pembinaan personel yang berwujud siklus pendidikan, penugasan, pelatihan yang berkelanjutan dan disesuaikan kebutuhan TNI AL (Ahmadi et al. 2018). Dengan adanya pelatihan aplikasi SIMAK-BMN pada personil Disbekal, serta motivasi dan kompetensi yang dimiliki oleh personil Disbekal diharapkan dapat berpengaruh dalam meningkatkan kinerja, membantu serta mempermudah organisasi, khususnya dalam mengerjakan tugas administratif serta penatausahaan oleh personel, sehingga dapat berjalan efektif dan efisien, serta dapat memenuhi ketepatan waktu serta kualitas pelaporan.

Dalam mencapai keberhasilan penyelenggaraan pelatihan dalam SIMAK-BMN, suatu instansi membutuhkan sistem pengendalian intern yang kuat agar dapat berjalan efektif. Pengendalian intern merupakan proses saling berkaitan pada kegiatan maupun tindakan yang dikerjakan secara kontinyu oleh seorang pimpinan beserta seluruh karyawan untuk memiliki keyakinan kuat dalam mencapai tujuan dari organisasi melalui kegiatan maupun tindakan secara efektif serta efisien dalam mengamankan aset dari negara, dan kepatuhan dalam menjalankan peraturan yang berlaku (Rahmawati, Mustika, and Eka 2018). Dimana faktor berpengaruh pada efektifitas serta efisiensi penggunaan aplikasi SIMAK-BMN yakni adanya kemudahan, tercapainya kegunaan dan terjaminnya kualitas sistem (Rahardiyanti 2005). Adanya pengendalian intern tersebut terhadap kualitas tenaga kerja yang baik, akan didapat kinerja yang baik pula yakni melalui pelatihan, sehingga diharapkan dapat menimbulkan kemampuan kerja yang lebih baik pada personilnya sehingga dapat berdampak positif bagi kinerjanya (Rudhaliawan,
Utami, and Hakam 2015). Agar mengetahui keberhasilan pelatihan personil Disbekal, baik sebelum dan sesudah melaksanakan pelatihan SIMAK-BMN. Adapun tujuan penelitian adalah menganalisis dan menjelaskan pengaruh pelatihan SIMAK-BMN (X1) terhadap peningkatan kualitas kinerja personil Disbekal $(Y)$, pengaruh motivasi $(X 2)$ terhadap peningkatan kualitas kinerja personil Disbekal (Y), pengaruh Kompetensi (X3) terhadap peningkatan kualitas kinerja personil Disbekal $(\mathrm{Y})$.

\section{METODE PENELITIAN}

Dalam penelitian ini menggunakan metode penelitian kuantitatif, dengan menggunakan pendekatan statistik dengan melakasanakan uji validitas, melaksanakan uji reliabilitas, melaksanakan uji asumsi klasik dan melaksanakan uji hipotesis. Dengan populasi penelitian ini terdiri dari 52 Satker BMN Mabesal, Staf Ban IV Progar Srenal, Staf Ban VI BMN Slogal, Subdis BMN Disbekal, Subdis APK Diskual dan personil bagian perencanaan Satker Mabesal sebanyak 320 orang. Menurut (Djarwanto, 2000), dasar rumus dalam menghitung jumlah sampel adalah:

$$
n=\frac{N}{1+N e^{2}}
$$

\section{Dimana:}

$\mathrm{n}$ : Ukuran Sampel

$\mathrm{N}$ : Ukuran Populasi

e : Persen kelonggaran

Adapun sumber data primer didapatkan melalui pelaksanaan kuesioner (Angket) kepada responden dengan memanfaatkan Google Form. Dengan tipe pertanyaan kuesioner yang peneliti gunakan adalah kuesioner tertutup, yang dilaksanakan pada bulan Maret hingga Mei 2021. Sedangkan, sumber data sekunder didapatkan dari observasi dan review literatur serta dokumen lain untuk menyajikan data dan informasi mengenai SDM dan organisasi SIMAK BMN. Teknik yang dipergunakan oleh peneliti dalam pengolahan data dengan program SPSS.

\section{HASIL DAN PEMBAHASAN \\ Karakteristik Responden Penelitian}

- Jenis Kelamin Responden

Responden terdiri atas 133 orang wanita atau sebesar $75 \%$ dan sisanya 47 orang pria atau sebesar 25 \%. Mayoritas responden Wanita dikarenakan pekerjaan dilakukan Sebagian besar berada di dalam ruangan. 


\section{- Usia Responden.}

Berusia antara 20-30 tahun sebesar $13 \%$ atau 23 orang, 30-40 tahun sebesar $30 \%$ atau 53 orang dan 40-48 tahun sebesar $57 \%$ atau 102 orang. Personel yang berusia muda diberikan penempatan di KRI untuk mendapatkan pengalaman di lapangan, sehingga yang mendukung administrasi di kantor adalah Sebagian besar berusia diatas 40-48 tahun.

\section{- Masa Kerja Responden}

Mayoritas masa kerja responden diatas 10 tahun sebesar $65 \%$, serta tidak mengalami pindah tempat tugas selama lebih dari 8 tahun secara berturutturut.

\section{- Pendidikan terakhir}

Mayoritas personel yang dijadikan responden memiliki Pendidikan setara sarjana/magister sebanyak $50 \%$ atau sejumlah 89 orang, Pendidikan setara diploma $40 \%$ atau 71 orang, dan setara SMA adalah $10 \%$ atau 18 orang.

\section{Uji Validitas dan Realibilitas}

Hasil dari uji validitas data yang dihasilkan sesuai Tabel 2. Berdasarkan tabel tersebut, didapatkan $r$ hitung dari variabel lebih dari $r$ tabel product moment yakni $>0,1476$ sehingga disimpulkan seluruh pertanyaan kuesioner dinyatakan valid. Nilai Cronbach alpha dari hasil uji reliabilitas memiliki nilai koefisien $>0,6$ maka instrumen dari penelitian adalah reliabel.

Tabel 2. Hasil Uji Validitas Data

\begin{tabular}{clccl}
\hline No & Variabel & $\begin{array}{c}\text { R } \\
\text { hitung }\end{array}$ & R tabel & Keterangan \\
\hline 1 & $\begin{array}{l}\text { Pelatihan } \\
\text { SIMAK-BMN } \\
(X 1)\end{array}$ & 0,764 & 0,1476 & Valid \\
\hline 2 & Motivasi (X2) & 0,671 & 0,1476 & Valid \\
\hline 3 & $\begin{array}{l}\text { Kompetensi } \\
\text { (X3) }\end{array}$ & 0,665 & 0,1476 & Valid \\
\hline 4 & $\begin{array}{l}\text { Kualitas } \\
\text { Kinerja } \\
\end{array}$ & 0,733 & 0,1476 & Valid \\
& $\begin{array}{l}\text { Personil } \\
\text { Disbekal (Y). }\end{array}$ & & & \\
\hline
\end{tabular}

Tabel 3. Hasil Uji Reliabilitas Data

\begin{tabular}{clcc}
\hline No & Variabel & Alpha & Keterangan \\
\hline 1 & $\begin{array}{l}\text { Pelatihan SIMAK- } \\
\text { BMN }(\mathrm{X} 1)\end{array}$ & 0,932 & Reliabel \\
\hline 2 & Motivasi (X2) & 0,917 & Reliabel \\
\hline 3 & Kompetensi (X3) & 0,853 & Reliabel \\
\hline 4 & Kualitas Kinerja & 0,820 & Reliabel \\
& Personil Disbekal (Y). & & \\
\hline
\end{tabular}

\section{Hasil Uji Analisis Statistik Deskriptif}

Rata-rata jawaban dari responden terkait indikator variable penelitian bernilai tinggi, yang artinya persepsi dari responden penelitian terhadap variabel pelatihan, motivasi, kompetensi dan kualitas kinerja personil disbekal adalah tinggi.

Tabel 4. Statistik Deskriptif Variabel Penelitian

\begin{tabular}{clcc}
\hline No & Indikator Variabel & $\begin{array}{c}\text { Rata-rata } \\
\text { Jawaban } \\
\text { Responden }\end{array}$ & Kriteria \\
\hline 1 & $\begin{array}{l}\text { Pelatihan SIMAK- } \\
\text { BMN (X1) }\end{array}$ & 3,98 & Tinggi \\
\hline 2 & Motivasi (X2) & 3,94 & Tinggi \\
\hline 3 & Kompetensi (X3) & 3,92 & Tinggi \\
\hline 4 & $\begin{array}{l}\text { Kualitas Kinerja } \\
\text { Personil Disbekal } \\
\end{array}$ & 4,05 & Tinggi \\
& & & \\
\hline
\end{tabular}

\section{Hasil Analisis Regresi Linier Berganda}

Tabel 5. Pengujian Regresi Linier Berganda

\begin{tabular}{|c|c|c|c|c|c|c|c|}
\hline \multirow[t]{2}{*}{ Model } & \multicolumn{2}{|c|}{$\begin{array}{l}\text { Unstandardized } \\
\text { Coefficients }\end{array}$} & \multirow{2}{*}{$\begin{array}{l}\text { Unstandardized } \\
\text { Coefficients } \\
\text { Beta }\end{array}$} & \multirow[t]{2}{*}{$\mathrm{t}$} & \multirow[t]{2}{*}{ Sig. } & \multicolumn{2}{|c|}{ Collinearity Statistics } \\
\hline & & Error & & & & Tolerance & VIF \\
\hline Konstanta & .817 & .753 & & 3.212 & .004 & & \\
\hline Pelatihan & .125 & .055 & .529 & 2.510 & .015 & .525 & 1.906 \\
\hline SIMAK-BMN (X1) & & & & & & & \\
\hline Motivasi (X2) & .465 & .098 & .148 & 6.725 & .002 & .640 & 1.563 \\
\hline Kompetensi (X3) & .247 & .055 & .284 & 4.398 & .001 & .710 & 1.408 \\
\hline RSquared & .496 & & F. Hitung & 56.635 & & & \\
\hline$R$ & .705 & & Sia, $F$ & .000 & & & \\
\hline
\end{tabular}

Berdasarkan tabel perhitungan analisis pada tabel 5 diatas, selanjutnya dibuat persamaan matematis yakni:

$$
\hat{Y}=0,817+0,125 X 1+0,1247 X 2+0,465 X 3
$$

Dalam hasil penelitian ditemukan tidak terdapat multikolinieritas antar variabel independen

\section{Hasil Analisa Uji-t}

Hasil perhitungan df $=\mathrm{n}-\mathrm{k}(178-3)=175$. Dimana nilai thitung dari pelatihan SIMAK-BMN (X1) adalah 2.510 dan $t$ tabel 1,6537, nilai koefisien Pelatihan SIMAK-BMN (X1) bernilai positif 0,125 . nilai t hitung $>\mathrm{t}$ tabel, berarti $\mathrm{H} 1$ diterima, maka Pelatihan SIMAK-BMN (X1) berpengaruh positif terhadap Kualitas Kualitas Kinerja Personil Disbekal $(\mathrm{Y})$.

Hasil perhitungan $d f=n-k(178-3)=175$. Dimana nilai t hitung dari Motivasi (X2) adalah 6.725 dan $t$ tabel 1,6537, nilai koefisien Motivasi (X2) bernilai positif 0,465 . nilai $t$ hitung $>t$ tabel, Berarti H1 diterima, maka Motivasi (X2) berpengaruh positif kepada Kualitas Kualitas Kinerja Personil Disbekal (Y). 
- Hasil perhitungan df $=\mathrm{n}-\mathrm{k}(178-3)=175$. Dimana nilai $\mathrm{t}$ hitung dari Kompetensi (X3) adalah 4.398 dan $\mathrm{t}$ tabel 1,6537, nilai koefisien Kompetensi (X3) bernilai positif 0,247. nilai $t$ hitung > t tabel, berarti $\mathrm{H} 1$ diterima, maka Kompetensi (X3) berpengaruh positif kepada Kualitas Kualitas Kinerja Personil Disbekal (Y).

Sehingga dari perbandingan hasil analisis regresi menunjukkan bahwa nilai koefisien regresi Motivasi (X3) lebih tinggi dari Pelatihan SIMAKBMN (X1) dan Kompetensi (X2) yakni 0,465 yang dapat diinterpretasikan motivasi merupakan faktor yang berpengaruh paling besar kepada kualitas kinerja Personil Disbekal, diikuti oleh Kompetensi (X2) dan Pelatihan SIMAK-BMN (X1).

\section{Hasil Analisa Uji Model (Uji F)}

Berdasarkan hasil analisis didapatkan nilai $F$ hitung sebesar 56,635 dan $F$ tabel 2,66. Nilai $F$ hitung > F tabel, dapat di interpretasikan bahwa pelatihan SIMAK-BMN, kompetensi dan motivasi bersama-sama berpengaruh pada variabel Kualitas Kualitas Kinerja Personil Disbekal.

\section{Koefisien Determinasi $\left(\mathbf{R}^{\mathbf{2}}\right)$}

Nilai koefisien determinasi (R2) didapatkan 0,496 . Artinya yakni Kualitas Kualitas Kinerja Personil Disbekal (Y) sangat dipengaruhi oleh variabel Pelatihan SIMAK-BMN (X1), Kompetensi (X2), dan Motivasi (X3) sebesar 52,5\%, adapun sebesar $47,5 \%$ dapat dipengaruhi faktor-faktor yang lain.

\section{Pengaruh dari Pelatihan SIMAK-BMN terhadap peningkatan Kualitas Kinerja Personil Disbekal}

Berdasarkan hasil analisis diatas, maka pelatihan SIMAK-BMN berpengaruh positif serta memiliki signifikansi tinggi terhadap peningkatan kualitas personel Disbekal. Sesuai dengan (Yusnita \& Rahdian, 2018) tentang Pengaruh Pelatihan terhadap kualitas Kinerja pada Karyawan di PT PDAM Kota Bogor. Dimana bertujuan untuk mengetahui pelaksanaan pelatihan, mengetahui tingkat pelayanan, serta menilai pengaruh pelatihan terhadap kinerja dari karyawan PT PDAM Tirta Pakuan Kota Bogor. Selanjutnya juga didukung oleh penelitian dari (Anggereni, 2018) tentang Pengaruh Pelatihan Terhadap Kinerja Karyawan Pada Lembaga Perkreditan Desa (LPD) Kabupaten Buleleng bahwasannya pengaruh pelatihan terhadap kinerja karyawan pada LPD Buleleng dengan koefisien determinasi 0,706 atau $70,6 \%$ kinerja karyawan dipengaruhi oleh pelatihan.

\section{Pengaruh dari Motivasi terhadap Peningkatan Kualitas Kinerja Personil Disbekal}

Salah satu faktor yang dapat meningkatkan kualitas kinerja Disbekal adalah motivasi. Pada dasarnya personel Disbekal yang sudah berdinas di Disbekal adalah personel yang sudah lama menempati jabatan tersebut, dan memiliki usia yang sudah tidak muda. Sehingga instansi Disbekal mengharapkan personil nya memiliki kemauan dan juga kemampuan untuk giat bekerja, serta memiliki motivasi tinggi dalam meraih tujuan dari organisasi, sehingga bila hanya memiliki kemampuan, ketrampilan dan kecakapan personel tidak akan ada gunanya bila tidak memiliki motivasi tinggi dari setiap personil guna meningkatkan kualitas kinerja. Penelitian ini sejalan (Anoraga, 2009) bahwa motivasi individu merupakan hal yang timbul pada diri seseorang dan dari luar untuk mendorong berbuat sesuatu dimana kedua hal tersebut berpengaruh terhadap perilaku dan prestasi kerja. Sejalan dengan (Suparno \& Sudarwati, 2012)yang mengungkapkan bahwa motivasi berpengaruh positif, dan sangat signifikan terhadap kinerja pegawai. Sehingga motivasi merupakan faktor terpenting, karena diharapkan setiap individu personel Disbekal memiliki kemauan untuk bekerja keras dan antusias dalam mencapai produktivitas kerja tinggi.

\section{Pengaruh dari Kompetensi terhadap Peningkatan Kualitas Kinerja Personil Disbekal.}

Kompetensi merupakan kemampuan dasar sesuai karakter individu yang mendasari kinerja atau perilaku yang seharusnya dimiliki personel Disbekal. Kompetensi ini sangat diperlukan untuk menunjang pelaksanaan inventarisasi, pelaporan dan penerapan SIMAK-BMN agar dapat memiliki hasil baik. Sehingga jika diimbangi bersama-sama dengan variabel lain, yakni pembukuan BMN dan system pelaporan keuangan sesuai ketentuan dan aturan yang dipersyaratkan, agar dapat menaikkan kualitas kinerja personil Disbekal menjadi lebih baik. Hasil ini sejalan dengan Anggreani (2015) dan Febrianti (2016) serta Isnain (2012) yang menyampaikan bahwa kompetensi dalam pembukuan, inventarisasi, dan pelaporan keuangan sehingga dapat berpengaruh positif terhadap kualitas kinerja pegawai. Sesuai juga dengan (Pandaleke, 2016) yang mengatakan bahwa 
kompetensi juga dapat berpengaruh terhadap peningkatan kinerja karyawan. Tetapi penelitian dalam artikel ini tidak sejalan dengan penelitian Diani (2014) yang menyampaikan bahwa pemanfaatan Sistem Informasi Keuangan tidak berpengaruh secara signifikan pada peningkatan kualitas pada laporan keuangan, dikarenakan Pemerintah belum sepenuhnya memanfaatkan sistem tersebut, padahal Sistem Informasi Keuangan adalah suatu alat yang digunakan pemerintah dalam memberikan informasi keuangan secara detail, akurat dan update. Seseorang pegawai atau karyawan yang memiliki kompetensi baik agar mampu menjalankan tugas-tugas dengan lebih cepat dan akurat yang dibebankan kepadanya, sedangkan kompetensi tersebut diantaranya berupa ketrampilan, kemampuan anlisa, pengetahuan sistem aplikasi, serta sikap yang sesuai serta seimbang dengan jabatan yang diemban agar termotivasi untuk bekerja lebih efektif, efisien dan produktif.

Secara keseluruhan bahwa hasil dalam penelitian kali ini sesuai dengan penelitian Lewa dan Subowo (2005) dan Pramudyo (2010), yang menyampaikan bahwa motivasi, kompetensi, pelatihan berpengaruh positif terhadap peningkatan kualitas kinerja.

\section{KESIMPULAN}

Berdasarkan hasil penelitian dan pembahasan mengenai pengaruh kompetensi, motivasi, dan pelatihan aplikasi sistem penatausahaan SIMAK BMN terhadap kualitas kinerja personil disbekal pada penelitian ini, sehingga dapat ditarik kesimpulan bahwa:

1. Pelatihan SIMAK-BMN berpengaruh positif terhadap Peningkatan Kualitas Kinerja Personil Disbekal.

2. Kompetensi berpengaruh positif terhadap Peningkatan Kualitas Kinerja Personil Disbekal.

3. Motivasi aktualisasi diri berpengaruh positif terhadap Peningkatan Kualitas Kinerja Personil Disbekal.

Secara teoritis dalam penelitian ini dapat memberikan pemahaman pentingnya pengaruh pelatihan SIMAK-BMN, motivasi, kompetensi terhadap personel Disbekal. Meskipun demikian masih terdapat keterbatasan dalam pengambilan sampel dari penelitian ini belum merata, dikarenakan ada yang berpusat pada satu kantor saja. Adapun saran yang dapat diberikan pada
Disbekal adalah agar dapat mengoptimalkan aplikasi SIMAK-BMN dalam meningkatkan kualitas kinerja Personel. Selain itu, Disbekal juga memerlukan kepemimpinan yang baik sesuai dengan perkembangan jaman yang dinamis, dimana kepemimpinan juga sangat berpengaruh, terkait harus mempunyai motivasi tinggi dan kreativitas tinggi agar dapat dicontoh oleh personel Disbekal. Sedangkan untuk penelitian selanjutnya disarankan menambah variabel lain yang memungkinkan dapat mempengaruhi dalam meningkatkan kualitas kinerja personel Disbekal, diantaranya seperti kompensasi, kerjasama tim, situasional dan lingkungan kerja, serta faktor Kepemimpinan.

\section{DAFTAR PUSTAKA}

Ahmadi, Putra, I. N., Suharyo, O. S., Ariyoko, H. B., \& Susilo, A. K. (2018). Strategi Pengembangan Sistem Pendidikan Dan Latihan TNI AL Dalam Mendukung Penguasaan Teknologi Keangkatanlautan 2030. Prosiding Seminar Nasional Kelautan dan Perikanan IV (hal. 134143). Surabaya: Universitas Trunojoyo Madura.

Amboningtyas . (2013). The influence of information asymmetry and budget emphasis on the relationship between participation and slack. Accounting and Business Research, 33(2), 91-104.

Anggereni, N. W. (2018). Pengaruh Pelatihan Terhadap Kinerja Karyawan Pada Lembaga Perkreditan Desa (Lpd) Kabupaten Buleleng. Jurnal Pendidikan Ekonomi Undiksha, 10(2), 606615.

Anoraga, P. (2009). Manajemen Bisnis. Semarang: PT. Rineka Cipta.

Arikunto, S. (2010). Prosedur penelitian: suatu pendekatan praktik (Edisi Revisi cetakan ke 14 ed.). Jakarta: Rineka Cipta.

Baron, \& Greenberg. (1997). Behavior in Organization Understanding and Managing The Human Side of Work (6th ed.). USA: Prentice Hall.

Demac, G. S., Andresa, P. S., Antonia, L. M., \& Avhthk, G. (2019). Information asymmetry in management research: Past accomplishments and future opportunitie. Journal of Management ,45(1), 122-158.

Djarwanto, P. S. (2000). Statistic Induktif (5th ed.). Yogyakarta: BPFE. 
Dramaji, Y. (2018). Analisis Budaya Organisasi Dan Asimetri Informasi Dalam Senjangan Anggaran. Jurnal Akuntansi dan Keuangan, 9(2), 78-88.

Edor, Y., Tamenor, G. J., Garbile, A. A., \& Hunton, H. (2016). Application of signaling theory in management research: Addressing major gaps in theory. European Management Journal , 34(4), 338-348.

Ellun, S., Julet, M., \& Antonius, H. (2014). A behavioral approach to the rational choice theory of collective action: Presidential address. American political science review, 92(1), 1-22.

Engar, F., \& Mamsah, T. Y. (2014). The effect of budgetary participation, assymetry information, budget emphasis and comitment organization to budgetary slack at skpd governmental of bengkulu city. Journal Of Accounting , 12(3), 450470.

Fun, H. C., \& Tawon, J. I. (2003). Countervailing power in empowered participatory governance archon fung and erik olin wright." Deepening democracy. Institutional innovations in empowered participatory governance, 4, 259.

Hutapea, Parulian, Thoha, \& Nurianna. (2008). Kompetensi Plus. Jakarta: PT Gramedia Pustaka Utama.

Irfan, M. B. (2016). Pengaruh partisipasi anggaran terhadap senjangan anggaran dengan asimetri informasi, penekanan anggaran dan komitmen organisasional sebagai variabel pemoderasi. Journal of Accounting and Investment, 172.

Maharani , A. R., \& Ari, D. (2014). Efek Mediasi Informasi Asimetris dan Moderasi Locus of Control pada Pengaruh Partisipasi Anggaran dan Penekanan Anggaran terhadap Budgetary Slack. Jurnal Akuntansi Multiparadigm, 13(2), 90-110.

Mc Dornot. (2014). The politics of institutional renovation and economic upgrading: Recombining the vines that bind in Argentina. Politics \& Society, 35(1), 103-144.

Nasir. (2017). Pengaruh Partisipasi Anggaran Terhadap Kinerja dan Prestasi Organiasi Yang Dimediasi Oleh Asimetri Informasi. Journal of Accounting and Investment, 11-23.

Ocksum, A. (2013). Toward a behavioral theory linking trust, reciprocity, and reputation." . Trust and reciprocity: Interdisciplinary lessons from experimental research, 6, 19-30.

Ocmosun, D. D., \& Andresa, C. D. (2010). Information asymmetry, $R \& D$, and insider gains. . The journal of Finance, 55(6), 2747-2766.

Pandaleke, D. (2016). Pengaruh Kompetensi, Kepuasan Kerja dan Komitmen organisasi Terhadap Kinerja pegawai (Studi Pada Inspektorat Kabupaten Minahasa Tenggara). Jurnal EMBA, 4(2), 199-210.

Pramudyo, A. (2010). Analisis Faktor-faktor yang Mempengaruhi Kinerja Dosen Negeri Dipekerjakan Pada Kopertis Wilayah $V$ Yogyakarta, 1(1).

Rahmiati. (2015). "Pengaruh Partisipasi Anggaran, Asimetri Informasi, Komitmen Organisasi, Ambiguitas Peran Terhadap Budgetary Slack. Accounting Analysis Journal , 4(4), 390-430.

Rivai, V., \& Sagala, E. J. (2009). Manajemen Sumber Daya Manusia Untuk Perusahaan. Jakarta: PT. Raja Grafindo Persada.

Robbins, S. P. (1996). Perilaku Organisasi. Jakarta: PT. Prenhallindo.

Santoso. (2016). Pengaruh partisipasi anggaran terhadap senjangan anggaran dengan asimetri informasi, penekanan anggaran dan komitmen organisasional sebagai variabel pemoderasi. Journal of Accounting and Investment, 17(2), 158275.

Selvi, H. (2016). "Pengaruh Partisipasi Penyusunan Anggaran Terhadap Kinerja Aparat Pemerintah Daerah Dengan Budaya Organisasi, Komitmen Organisasi, Motivasi, Desentralisasi, Dan Job Relevant Information Sebagai Variabel Moderasi. Journal of Accounting and Investment, 12(2), 197-207.

Sugiono. (2016). Metode Penelitian Kuantitatif. Jakarta: Erlangga.

Suparno, \& Sudarwati. (2012). Pengaruh Motivasi, Disiplin Kerja, Dan Kompetensi Terhadap Kinerja Pegawai Dinas Pendidikan Kabupaten Sragen. Jurnal Paradigma, 17.

Venusita, L. (2018). Partisipasi Anggaran dan Keterlibatan Kerja terhadap Senjangan Anggaran dengan Komitmen Organisasi sebagai Variabel Moderasi (Studi pada Perusahaan 
Industri Food and Beverage di Kawasan Industri SIER). Jurnal Kewirausahaan, 2(1), 27-43.

Wati. (2017). Pengaruh Partisipasi Anggaran Dan Penekanan Anggaran Terhadap Senjangan Anggaran Dengan Asimetri Informasi Sebagai Variabel Intervening (Studi Pada PT Kereta Api Periodetahun 2012-2016). Journal Of Accounting, 14(1), 56-69.

Yemis, A. A., \& Kunci, K. H. (2016). Budgetary participation in Turkey: The effects of information asymmetry, goal commitment, and role ambiguity on job satisfaction and performanc. Journal of International Accounting Research, 12(1), 29-45.

Yoana, Y. H. (2018). Pengaruh Asimetri Informasi Terhadap Budgetary Slack Dengan Kejujuran Sebagai Variabel Pemoderasi: Penganggaran
Partisipatif. EKOMBIS REVIEW: Jurnal Ilmiah Ekonomi dan Bisnis,, 9-18.

Yusnita, N., \& Rahdian, R. (2018). Pengaruh Pelatihan Terhadap Kinerja Karyawan Pada Pt Pdam Tirta Pakuan Kota Bogor. JIMFE (Jurnal Ilmiah Manajemen Fakultas Ekonomi), 6, 78-83. doi:10.34203/jimfe.v6i1.481 